
doi: $10.1093 /$ jae/ejh023

\title{
Collective Action, Heterogeneous Loyalties and Path Dependence: Micro-evidence from Senegal
}

\author{
Jean-Philippe Platteau ${ }^{\mathrm{a}}$ and Tomasz Strzalecki ${ }^{\mathrm{b}, 1}$ \\ ${ }^{\mathrm{a}}$ University of Namur and ${ }^{\mathrm{b}}$ Northwestern University
}

In Senegal, we encountered a situation in which a minority group of migrant fishermen had completely different sets of expectations regarding a collective action depending on the location where they operated. In one village expectations were pessimistic, while in the other village they were optimistic. Understanding this contrast and its implications provides the main justification for the paper. To be able to account for the contrast between the two areas, pessimistic expectations in the first area have to be traced back to a preceding conflict that could never be settled satisfactorily. A perverse path-dependent process had thus been set in motion that could not be changed by a simple act of will of a determined leadership. To demonstrate the links between expectations and actions that fit with the story told, we propose a simple model of collective action with asymmetric information.

\footnotetext{
${ }^{1}$ Jean-Philippe Platteau is Professor of Economics at the University of Namur and Tomasz Strzalecki is at the Department of Economics, Northwestern University. This study would not have been possible without the financial support of the Fondation Universitaire pour la Coopération Internationale au Développement (FUCID) at the University of Namur. Its support is gratefully acknowledged, as is the collaboration of the partner institutions in Senegal: the Centre de Recherche et de Développement de Technologies Intermédiaires pour la Pêche (CREDETIP) and the Collectif National des Pêcheurs Sénégalais (CNPS). The latter played a major role in facilitating our preliminary contacts with the surveyed fishing communities and demonstrated great willingness to exchange views with us. Ousseynou Dieng, researcher at the CREDETIP (Centre de Recherche et Développement sur les Technologies Intermédiaires de Pêche), was a key performer at the level of data collection and coding. François Migeotte and Catherine Mélard, both from CRED, were direct collaborators of Ousseynou Dieng, and made an important contribution to the collection, coding and processing of the data, as well as to the writing of insightful field notes and preliminary reports. Finally, thanks are due to Jim Robinson, Paul Collier, Jean-Paul Azam and Jean-Claude Berthelemy for helpful comments.
} Economies 2004; all rights reserved 


\section{Introduction}

Ethnic conflict is a generic term that encompasses violent outbursts between groups with different identities, whether the source of differentiation lies in religion, race, language, culture or regional affiliation. Recently, there have been some attempts to use rational choice theory and, in particular, the game-theoretical approach of economics to highlight some aspects of ethnic conflicts. One privileged way of enriching our understanding on the basis of such an approach is to emphasise the role of expectations, considering that pessimistic expectations may unleash ethnic violence even though there are no objective grounds for conflicts of interest between the contending parties (Bates et al., 1998; Weingast, 1998). Thus, when a group fears victimisation by another, it may become an aggressor in order to preempt the other group from attacking. The bad outcome is all the more likely to occur if a cynical politician is ready to exploit people's ignorance with the goal of building up his own career. He will then strive to instill negative expectations vis-à-vis others in an identifiable segment of the population so as to reinforce their particularistic identity feelings and thereby mobilise their votes in political contests.

Instead of explaining tragic situations of destruction and killing, the expectation-driven approach can be used to account for situations where collective action fails to take place even though it is badly needed. In this case, members of one group refrain from, say, constructing a public good just because they fear that members of the other group will free ride on their efforts. Whichever the problem addressed - the production of a public bad or the missing production of a public good - it is important to bear in mind that, as long as expectations are exogenous, what is being highlighted is only the mechanism that triggers the conflict or the collective action failure. The fundamentals behind the problems cannot be grasped unless we understand the process of expectation formation.

By treating currently pessimistic expectations as the outcome of a preceding conflict game, the analysis can be deepened. However, if this game is also expectation-driven and expectations underlying this preceding game are exogenous, we need yet another game to explain them and the infinite regression problem arises. As a consequence, we do not provide an explanation of the origin of the conflict, but only of its persistence. (For a similar point, see Basu et al., 1987.) Yet, if one of the preceding conflict games is not expectation-driven, but represents 
a real conflict of interests, the regression ends and the ultimate cause of the conflict is revealed.

In Senegal, we encountered the following puzzling situation: two groups of fishermen, a minority group of migrant fishermen from Saint-Louis and a majority group of native fishermen, did not share the same degree of optimism regarding the chances of success of a joint collective action in one area (Kayar), while expectations of the same two groups regarding the same collective action were similar in another area (Soumbedioune) where the two groups also coexisted. In this paper, we argue that such a contrast can be accounted for by tracing back the pessimistic expectations of migrants in Kayar to a preceding conflict game which opposed a fraction of them to native fishermen. No such conflict occurred in Soumbedioune.

The aim of this paper is to tell this story in some detail, and to illustrate the importance of expectations for interaction between groups with different identities. Section 2 describes the history of conflict and cooperation as it unfolded in Kayar during the last decades, providing the essential background of the paper. Two major steps can be distinguished. First, the original conflict opposing two groups of fishermen, native fishermen on the one hand and a category of migrant fishermen using a special sort of fishing gear on the other, is explained and characterised. Subsequent attempts to resolve it are then briefly reviewed. Secondly, attention is shifted to the emergence of a rather unique opportunity of collective action capable of healing the wounds of the previous conflict, namely the formation of a cartel aimed at reducing the market power of the local fishmerchants or commission agents.

In Section 3, we address the question of whether expectations regarding the chances of success of the output-limiting scheme put into place by the fishermen of Kayar have been influenced by the previous traumatic experience of conflict. On the basis of information obtained from a household survey (conducted between April and July 1997), and qualitative insights gained from conversations with fishermen, it is argued that the trauma has not been erased. The scars that it left behind affected not only the category of migrant fishermen most directly concerned but the whole group of migrants operating in Kayar.

In Section 4, we examine the consequences of these pessimistic expectations for the fishermen's behaviour vis-à-vis the output-limiting scheme. Towards this purpose, we present a simple model of collective 
action. One of the players in the game is a third party agency that corresponds to the committee which the fishermen of Kayar have put into place to enforce the rules of their cartel. In the game, an assymetry of information exists about the impartiality of the committee. The inefficient, non-unique equilibrium of such a game is consistent with the high incidence of rule violations as perceived by the fishermen. Section 5 concludes the paper.

\section{The Original Conflict and the Subsequent Opportunity to Overcome it}

\subsection{The Original Conflict as a Tragedy of the Commons}

In Kayar, an important fishing village located in central Senegal, competition for access to inshore waters has been a constant source of tensions between native fishermen and migrant fishermen originating from Saint-Louis in the north of the country. An open conflict actually opposed a category of these migrant fishermen who operate bottom-set nets on the one hand, and indigenous fishermen using lines and purse seines on the other. While bottom-set nets are gill nets specially designed to catch fish on the bottom of the sea, ${ }^{2}$ purse seines are nets characterised by the use of a purse line at the bottom of the net which allows the net to be closed like a purse and to thus retain the fish caught. The conflict is akin to a 'Tragedy of the Commons' game. In the perception of the native fishermen at least, owing to the entry of migrant fishermen, returns to additional fishing effort are decreasing in the area suitable for bottom-set nets. There may even exist a point at which marginal productivity of fishing effort becomes nil so that a zero-sum game is being played.

The most common reaction of the native group in this sort of situation is to try to bar the migrant group from access to the contentious resource area. In this way, the Nash equilibrium that would obtain in the open access situation is prevented from getting established and the per capita income of the remaining resource users is increased while the degree of inefficiency in the exploitation of the

${ }^{2}$ Gill nets are a type of gear designed to gill, entangle or enmesh the fish. They may be used to catch fish on the surface, in midwater or on the bottom. In the latter case, they are called bottom-set nets. 
resource is reduced. The extent of these improvements will depend on the ratio of the number of expelled (migrant) fishermen to the number of indigenous ones. Such an outcome was nonetheless made difficult by two circumstances. First, bottom-set net operators from Saint-Louis happen to be completely specialised in the use of this gear. As a result, their livelihood entirely depends on the incomes thus earned during the period of their migration in Kayar.

Secondly, resistance on the part of migrant fishermen was heightened by the fact that different conceptions of sea tenure prevail among the two groups. Fishermen from Saint-Louis have a long tradition of mobility along the West African coast, a result of the fact that the fishing zone of Saint-Louis (Guet Ndar) is not sheltered from the strong winds of the Atlantic Ocean and is therefore accessible only during a limited part of the year. As a consequence of deep-rooted migration habits, these people tend to consider the sea as an open access resource that does not belong to any community in particular. People from Kayar have an almost opposite conception of sea tenure: being originally an agricultural community with lands located not far from the sea, they are inclined to view the adjacent water space as their own territory, much in the same way as they see their agricultural lands.

It is easy to understand why, in such circumstances, native fishermen of Kayar became quite aggressive against bottom-set net operators whereas the latter fiercely resisted any attempt at dislodging them from their area of operation. Anger on the part of Kayar natives was all the more acrimonious as they could blame migrant fishermen not only for causing a decline in their catches, but also for destroying their gears. The problem is that the active gears used by Kayar fishermen are particularly liable to be damaged by the migrants' passive gears (bottom-set nets) since both are put into operation within a rather overcrowded area. In fact, active gears risk being entangled into passive gears placed on the bottom of the sea and tied to buoys serving as landmarks for their owners.

As could have been predicted, the situation soon degenerated into acts of physical violence and several death casualties occurred in the course of the year 1985. Public authorities could not remain passive in the face of these tragic events that could all too easily lead to even more widespread disorder. In February 1986, therefore, the government of Senegal set up a special commission charged with the task of defining 
and monitoring an exclusive fishing zone, marked by buoys, in which bottom-set nets were to be prohibited from operating. ${ }^{3}$

Unfortunately, conflicts between bottom-set net operators and other fishermen remained pervasive as illegal encroachments upon the exclusive zone were quite frequent. In most cases, they were not dealt with by the commission partly due to a lack of monitoring equipment. ${ }^{4}$ In 1990, fishermen's leaders from the two communities decided to take more initiative and, with the support of some outstanding public authorities (such as the governors of Saint-Louis and Thies, and the General Khalife of the Muslim brotherhood of the Layènes in Yoff), they created the Comité de solidarité Kayar-Guet Ndar with a view to assuming more responsibilities in the monitoring operations and conflict resolution mechanisms. Results, however, remained quite below the expectations generated by this inter-community solidarity movement. Apparently, one important reason behind this failure is the fact that operators of the technique used by migrants in the highly contentious inshore area (the bottom-set net) were not represented in the conflict-management committee.

\subsection{Uniting against the Merchants: a Unique Opportunity to Erase the Scars of the Past}

In the early nineties, a special opportunity arose of forging solidarity ties among all fishermen operating in Kayar and thereby healing the wounds caused by the aforementioned conflict of resource access in the inshore waters. It was an especially worthy opportunity because it involved the fishermen in a collective struggle against a common enemy, namely the fishmerchants. Such a struggle was motivated by the former's determination to encroach upon the market power wielded by the latter so as to raise producer prices for the fish landed on the beach. It is in 1992 that, under the impulse of the Comite de solidarité Kayar-Guet Ndar, leaders from the community of native fishermen of Kayar and from the community of (temporary) migrant fishermen from Saint-Louis launched a first attempt to limit harvesting

${ }^{3}$ This commission is composed of four members, namely the chief of the local fisheries administration, the head of the local gendarmerie squad, and one representative of each fishing community (resident and migrant fishermen).

${ }^{4}$ The commission had received a canoe equipped with an outboard engine for surveillance operations, yet the boat could not be operated because of a lack of working capital for fuel expenses and maintenance of the equipment. 
efforts with a view to driving up the prices negotiated with the fishmerchants (known as mareyeurs in Senegal).

Initially, only one of the three fishing techniques in use in Kayar was concerned by the output-limiting scheme, namely purse seine fishing. Handled by big canoes moved by outboard engines, this technique is aimed at catching pelagic species destined to be largely sold on local markets (possibly including markets in neighbouring countries). ${ }^{5}$ The decision was that purse seine canoes would be allowed to make a single trip per day during the season suitable for this type of fishing. A special committee, named Comite des sennes tournantes (committee for purse seines), was established to ensure proper enforcement of the rule. The scheme has persisted to this date.

Two years later (1994), the so-called Comité des pêches (committee of the fisheries) has been set up by the fishermen of Kayar to replicate the experience of purse seines in the case of line fishing (operated from canoes of a smaller size) which targets demersal species destined for export markets. Such a step was taken soon after the devaluation of the CFA - the money used throughout the West Africa's monetary zone, then pegged to the French franc and guaranteed by France's Central Bank - when fishermen started fearing a severe contraction of their profit margins owing to a rapid rise of their production costs (in particular, the cost of fuel and the price of imported fishing equipment). Output prices did not rise significantly either because the species concerned were not of an exportable variety, or because fish intermediaries succeeded in appropriating a large share of the gains from devaluation.

Talks with management staff of fish-processing factories in Dakar confirmed that commission agents in charge of purchasing raw fish on the landing sites on behalf of export companies colluded with the purpose of preventing prices paid to the producer from increasing after devaluation. The system of payment applied by these companies actually encouraged trade malpractices, since they used to pay a predetermined price per unit weight (based on world market prices) to their commission agents, leaving them free to appropriate any residual gain obtained by underpaying fishermen. In other words, the

\footnotetext{
${ }^{5}$ Pelagic fishes spend most of their life swimming in the water column and have little contact with or dependency on the bottom. Pelagic fishes are often species that have reached their adult stage. By contrast, demersal fishes live in close relation with the bottom and depend on it.
} 
fish merchants were able to deprive fishermen of the beneficial effects of devaluation.

In reaction to such glaring manipulations of market prices by the fish merchants, fishermen started to demonstrate, first in Yoff (near Dakar) and soon thereafter in Kayar where the protest movement took on the form of a strike stretching over three consecutive days during which fishmerchants were starved of fish. Fishermen of Kayar demanded prices five to ten times higher than those offered them by the mareyeurs! Since merchants refused to raise their prices substantially after fishermen went back fishing, the latter decided to sell the fish themselves to the factories by renting in refrigerated vans and transporting the raw produce to Dakar. This was nevertheless a temporary solution soon succeeded by a systematic attempt to limit catches of demersal species through the fixing of a maximum number of boxes of fish that a canoe is allowed to unload on the beach for disposal. Most of the time, the number of boxes is set at three, yet the Comité des pêches can increase or decrease the quota depending on prevailing demand and supply conditions. In practice, the quota per canoe never falls below two boxes of fish, because fishermen consider that line fishing cannot be profitable if catches are smaller than this.

Clearly, such a scheme proved longer-lived than lock-out movements - which are hard to maintain given the lack of intertemporal markets to smoothen temporary disruptions of economic activity and direct sales of fish to export companies - which confront fishermen with considerable costs due to their lack of experience and skills in marketing.

\section{Past Trauma, Loyalty Feelings and Present Expectations}

\subsection{Divergent Beliefs about Economic Effects of Effort Regulation}

To what extent were the expectations regarding effort regulation influenced by memories of past traumatic conflict around the use of bottom-set nets by migrant fishermen from Saint-Louis? To answer that question, we need to determine whether there is a difference of perception between native and migrant fishermen, it being understood that migrant fishermen include not only the bottom-set net operators, but also the users of purse seines and lines. It must be borne in mind that effort regulation has not been attempted for use of bottom-set nets, which has been at the forefront of the historical conflict of 
resource access in the inshore waters. By asking whether purse seine and line fishermen from Saint-Louis, who have not directly suffered from that conflict, have more negative expectations than native fishermen about the outcome of output-limiting schemes, we want to know if their assessment of the present collective action has been shaped by their feelings of sympathetic loyalty toward (allegedly) victimised brethren.

Since attempts at effort regulation in Kayar were historically motivated by the objective of countering the fishmerchants' market power, fishermen were explicitly asked whether they believed that objective had been effectively attained, that is, whether catch limitations actually resulted in higher producer prices. Because the answers are very heterogeneous (see below), they may not only reflect the opinion about the objective result of the cartel, but also reveal ex ante expectations. If beliefs about cartel effectiveness were formed solely on the basis of the commonly observed variable, producer prices, no significant differences should be noticed, except those arising from varying levels of understanding of the economic mechanism at work.

There is actually a striking difference between the proportion of native fishermen (almost $80 \%$ ) and the proportion of migrant fishermen (only 44\%) who professed a belief in the economic impact of the attempted output-limiting schemes. It could be the case that other characteristics correlated with the identity of the respondent are responsible for this result. To control for this possibility, we have estimated an econometric logit model in which, besides the identity variable reflecting the migrant or non-migrant profile of the fishermen, several other plausible determinants of their beliefs have been introduced, including fishing gear used and education (since education can influence the degree of understanding of the market mechanism).

The dependent variable, effect, is a dummy variable with value equal to one when the fisherman has argued in a convincing manner that the kind of effort-limiting scheme at work in Kayar yields positive economic effects in the form of increased producer price, and equal to zero otherwise. The identity variable, migrant, is also a binary variable: it is equal to one when the fisherman is a migrant and zero when he is a native of Kayar. The results are presented in Table 1.

Before looking at the results, two methodological remarks are in order. First, owing to the restricted size of the sample, the confidence intervals yielded by the logit estimation procedure are not reliable. We 
Table 1: A Logit Estimate of the Determinants of Fishermen's Beliefs in the Economic Effect of Effort Regulation

Logit estimates

Log likelihood $=-36.056219$

Number of observations $=63$

Pseudo $\mathrm{R}^{2}=0.1669$

(standard errors adjusted for clustering on tech)

\begin{tabular}{|c|c|c|c|c|c|}
\hline Effect & Coef. & SE & $\mathrm{z}$ & $P|z|$ & $90 \% \mathrm{CI}$ \\
\hline Migrant & -1.867322 & 0.5856981 & -3.19 & 0.001 & $\begin{array}{l}-20.09811 \text { to } \\
-1.307114\end{array}$ \\
\hline Education & 0.6208494 & 0.457249 & 1.36 & 0.175 & $\begin{array}{l}0.1859989 \text { to } \\
17.66876\end{array}$ \\
\hline Crew1 & -2.257239 & 0.1860673 & -12.13 & 0.000 & $\begin{array}{l}-2.703181 \text { to } \\
-2.013583\end{array}$ \\
\hline Purseseine & 1.375369 & 0.8052276 & 1.71 & 0.088 & $\begin{array}{l}0.6540626 \text { to } \\
3.10568\end{array}$ \\
\hline Exclusive & -0.714173 & 0.6251002 & -1.14 & 0.253 & $\begin{array}{c}-1.565092 \text { to } \\
0.6931472\end{array}$ \\
\hline Otherincome & -1.406493 & 0.306259 & -4.59 & 0.000 & $\begin{array}{l}-18.53301 \text { to } \\
-0.900291\end{array}$ \\
\hline Constant & 0.9793271 & 1.080402 & 0.91 & 0.365 & $\begin{array}{l}-1.138221 \text { to } \\
3.096876\end{array}$ \\
\hline
\end{tabular}

have therefore opted for bootstrapping, which consists in drawing with replacement in the original sample to get a new sample of the same size, for which the estimation is performed. By doing so many times, an empirical distribution is generated for each estimated coefficient (here we chose $90 \%$ confidence intervals). Confidence intervals may then be constructed without any assumption about asymptotic distributions. Secondly, our bootstrap procedure takes into account the clustered sampling approach followed during our fieldwork, that is, the fact that the sampling procedure took place in two successive steps: the purposeful selection of the fishing techniques on the one hand, and the random selection of household within each selected technique on the other. Two-stage, clustered sampling has a non-trivial effect on the confidence intervals of the estimated 
coefficients, even though it does not affect the values of these coefficients.

As is evident from the results displayed in the table, after allowing for a number of other possible influences, migrant fishermen turn out to have a significantly more pessimistic assessment of the economic effects of effort regulation than native fishermen. (As explained above, the confidence intervals obtained through bootstrapping are used to make a judgement about statistical significance). Therefore, it seems that past traumatic events affecting a fraction of the migrant population have actually shaped the expectations of other migrant fishermen who feel emotionally close to them.

An apposite counterfact is provided by the village of Soumbedioune, an important port for small-scale fishermen near Dakar. There, as in Kayar, migrants from Saint-Louis coexist with local fishermen, yet, since ecological constraints prevent the use of purse seines and bottom-set nets around Dakar, line fishing is the only technique available. Furthermore, no effort limitation scheme has been tried in Soumbedioune, even though the prospect of doing so is being debated. Interestingly, the proportion of fishermen anticipating positive economic effects from the operation of such a scheme does not significantly differ between permanent residents and migrants from Saint-Louis: whereas it works out to almost $76 \%$ for the former, it is almost $70 \%$ for the latter. These proportions are remarkably close to the proportion of $80 \%$ observed among resident fishermen of Kayar (see Table 2).

This finding appears to confirm the view that something specific to Kayar accounts for the pessimism of migrant fishermen operating from this village. Since Soumbedioune did not experience the severe inter-community tensions caused by the use of bottom-set nets in disputed waters, such as happened in Kayar, local history of conflict and cooperation suggests itself as the key determinant of the shape of subsequent expectations about collective action outcomes.

\subsection{The Link between Reported Beliefs and Prior Beliefs}

It could be objected that, since we have measured expectations after several years of operation of effort regulation, we cannot be certain that they represent prior beliefs held at the start of the scheme. Because what we are in fact measuring are updated, posterior beliefs, it could be the case that migrants from Saint-Louis were optimistic at the 
Table 2: Proportions (\%) of Fishermen with a Positive Assessment of Effort

Regulation, According to Migrant/Native Status and to Geographic Location

Kayar Soumbedioune

Native fishermen

80

76

Migrant fishermen from Saint-Louis

44

70

starting of the scheme, yet adjusted their expectations in a pessimistic direction following repeated observations of rule breaking. However, as Section 4 shows, it is the prior beliefs that matter for the outcome of the effort regulating game. Therefore, for our analysis to be meaningful, we need to make sure that the group of migrants was pessimistic before the game started, not only after the collective action failed.

There are two reasons why we do not think that this alternative interpretation - according to which migrant fishermen were optimistic at the start of the scheme, yet became pessimistic over time as the experiment was unwinding - is valid. First, if what we observe are posterior beliefs, they must have been derived from priors through some process of updating. What we find, however, is that perceptions of rule breaking are essentially similar in both categories of fishermen: about the same proportion of people in each category believe that rule violations are frequent, and this proportion is actually quite high (see below). This means that the information used for updating by both categories of fishermen is the same. ${ }^{6}$ If the migrant fishermen revised their expectations pessimistically following repeated observations of

${ }^{6}$ It is true that the fishing technique used (purse seines or lines) influences fishermen's assessment regarding the extent of rule breaking, and that correlation between technique and the category of fishermen could create a spurious effect. The relationship between technique and perceptions of rule breaking reflects the fact that it is much easier to detect rule violations when the rule consists of a maximum number of fishing trips per day (a highly visible action) than when it is based on a maximum quantity of fish allowed to be landed (it is, indeed, not too difficult to conceal part of the landings from sight, especially if fish is discreetly disposed of while the boat is still out at sea). Yet, even after duly controlling for the technique used, the above result continues to hold: there is no statistically significant difference in the perceptions of rule violations between native and migrant fishermen (for more details, see Gaspart and Platteau, 2004). 
rule breaking, the local fishermen must have done it likewise. Therefore, because the posterior beliefs are more pessimistic for migrants than for the local fishermen, it must be the case that their prior beliefs were also more pessimistic. A complementary argument is presented in Section 4.3, where we use the link between prior beliefs and the outcome of the game to strengthen our inference about priors.

The second reason to believe in the ex ante pessimism of the migrants is the fact that their distrust not only concerns the particular case of effort regulation, but also extends to other cases of cooperation with local fishermen. In the course of meetings aimed at discussing new collective actions outside the realm of effort regulation, namely mutual sea rescue associations or informal savings schemes, one of the authors (J.-P.P.) observed significant resistance on the part of some migrant fishermen against proposals of joint action. Thus, the discussion could become suddenly sour when a fisherman from Saint-Louis interrupted a leader native of Kayar by reminding him of the bitter conflict around bottom-set nets and the deep scars it left on the migrant community. The trouble-maker would then be abruptly silenced on the ground that this conflict had been definitely settled and that it was therefore inopportune to rejoin the problem in a public meeting. What such situations reveal is that reconciliation between native and migrant fishermen following the tragic events of the year 1985 has been more apparent than real. There was still much room for suspicions and pent-up frustrations, especially on the part of the migrants, who felt marginalised by the strong native elite of Kayar village. It is only in the privacy of their home compounds that they dare give full vent to lingering ill-feelings.

It is not coincidental that, in these emotionally charged circumstances, our field survey generated a lot of turmoil among the native leadership of Kayar village, turmoil that eventually caused our enumerators to be declared persona non grata. Even the determined intervention of the director of the research project (J.-P.P.), who was himself a long-standing acquaintance of several local leading fishermen, could not reverse the situation. Revealingly, the main accusation brought against the enumerators was that they contributed to embitter the relationships between native and migrant fishermen by lending a complacent ear to their grievances regarding past events, and what was considered as unjustified pessimism and mistaken distrust in local collective endeavours. In so doing, they were alleged to help keep alive the memory of sinister events that would be better 
forgotten and, thereby, to undermine the efforts made by the Kayar leadership to unite all the operating fishermen in a common struggle to improve their livelihood.

The sin committed by the enumerators thus consisted of having listened to the privately expressed opinions of (migrant) fishermen who dared question present attempts to limit output in the light of past failures, while local leaders were striving to suppress such expressions of discontent, and acting as though they did not exist. This elite's tactic of strong denial of diverging appraisals actually reflects their voluntaristic approach to collective action. Also revealing of such a tactic is the fact that leading fishermen of Kayar (well-to-do fishermen owning several purse seines and having at least three wives) tend to be much more optimistic than other categories of fishermen when asked to assess the incidence of rule violations under the effortlimiting schemes (Gaspart and Platteau, 2004).

Reassurances that the results of the household survey would not be used against the local fishermen organisations but, on the contrary, would be put at their disposal for improving their mode of operation wee unproductive. The workshop that was eventually organised to report and discuss the results (in the absence of the enumerators) proved to be a disappointing experience: essentially, we were told, things were going well and the output-limiting scheme did not require any sort of adjustment. Fishermen harbouring dissenting views are just frustrated individuals eager to resurrect the (traumatic) past by referring to the bottom-set net conflict and the failure of local organisations to bring it to a satisfactory end. They are dangerous because they do not hesitate to utter their grievances at the risk of destroying the valuable achievements of the fishing committees set up towards limiting fish harvests.

To sum up, the presence of control variables in the regression presented in Table 1 enables us to draw the following conclusion: the effect of migrant status or identity on the fishermen's beliefs regarding the economic effect of effort regulation is not an artefact caused by an association between migrant status and some other factor that directly bears on such beliefs. The contrast between the pessimistic and optimistic expectations held by a same group of migrant fishermen in two locations (Kayar and Soumbedioune), exposed to different histories provides strong support, amply confirmed by qualitative evidence obtained in the course of the fieldwork, in favour of the following hypothesis: the pessimistic expectations observed among 
migrant fishermen in Kayar have been shaped in a decisive manner by the legacy of inter-community resentment born of a severe conflict affecting a subgroup of these fishermen (the bottom-set net operators). Identity or community feelings ensured that the victimisation experienced by the subgroup spread throughout the entire group of migrant fishermen residing in Kayar.

\subsection{Ancillary Results}

Let us now shortly comment the econometric results pertaining to the control variables present in the regression.

First, fishermen working with purse seines appear to be more convinced than other fishermen that effort regulation has the intended impact. (Purseseine is equal to one when the operated technique is a purse seine, and to zero when it uses lines or bottom-set nets.) This finding can be ascribed (i) to the comparatively easy monitorability of effort regulation in the case of purse seines, which are regulated on the basis of fishing trips rather than quantities landed (see above); and (ii) to the presence of all local leaders and initiators of the output-limiting schemes among the stratum of purse seine owners.

Secondly, compared to asset owners, crew labourers on canoes using purse seines are less inclined to believe that output limitation can result in higher producer prices. ${ }^{7}$ (Crew1 is equal to one when the fisherman works as a crew labourer with a purse seine, and to zero otherwise, while Crew2 is equal to one when the fisherman works as a crew labourer with lines or bottom-set nets, and to zero otherwise.) This is probably due to the fact that many such crew are not professional but only part-time fishermen with comparatively low fishing skills and little acquaintance with the fishing trade. The variable Crew2 does not figure out in the table because it is a perfect predictor: in contrast to what we observed for purse seine crew, the highly skilled and full-time labourers handling lines or bottom-set nets have all admitted to the economic impact of effort regulation. ${ }^{8}$ The

${ }^{7}$ Since the crew is paid according to a predetermined share of the catch proceeds, they ought to benefit from any increase in the catch proceeds resulting from output limitation. Other things being equal, there is thus no ground to expect crew labourers to differ from equipment owners in their assessment of the economic impact of an output-limiting scheme.

${ }^{8}$ Bear in mind that, if all owners of bottom-set nets are migrant fishermen from Saint-Louis, this is not necessarily true of the crew handling those nets. 
corresponding observations have therefore been removed from the sample used for the final estimation and bootstrapping.

Third, fishermen who have alternative income sources available to them are also less persuaded that effort restrictions can yield economic benefits. (The variable Otherincome takes on value one if at least one member of the household earns some income from an activity other than fishing proper, and/or when the household owns some agricultural land or more than one house from which rental incomes can possibly be earned.)

Here, the prediction from economic theory is actually ambiguous. On the one hand, when they can rely on complementary sources of income, fishermen are expected to be more supportive of effort regulation because they are better able to endure the loss of fishing incomes in the short or medium term so as to benefit from higher incomes in the long term. Yet, on the other hand, fishermen with greater alternative income opportunities may pay less attention to their fishing incomes and feel less ready to incur sacrifices in order to increase them. This is all the more so if alternative incomes originate in fish marketing (usually by the fishermen's wives), since gains accruing to fishermen under the form of increased unit prices must then be weighed against the losses suffered by fishmongers within the household. The result obtained in Table 1 suggests that the latter effect actually predominates, not a surprising conclusion given the inherently conflicting interests between fish harvesters and fish distributors that we have just mentioned.

Fourth, education does appear to affect fishermen's beliefs regarding the impact of effort restriction, and the sign of the coefficient is positive as expected. (The variable Education is set to one when the fisherman has gone through at least six years of French or Koranic schooling, and to zero otherwise.) Note that alternative definitions of this variable (including continuous measurements) do not alter the reported result.

Finally, involvement in sales-tying debts has no significant influence on fishermen's judgement. (Exclusive takes unit value when the fisherman is involved in sales-tying debts with a particular fishmerchant, and zero value otherwise.) It is indeed a common feature of many small-scale fisheries in developing countries that productive loans may be given to fishermen on the explicit condition that their catches will be disposed of through the lender-merchant and interest payments will be typically subtracted from the sale proceeds, possibly 
in the form of reduced purchase prices. In this way, merchants try to secure themselves a sufficient supply of raw material to keep their business running (see Platteau and Abraham, 1987; Platteau and Nugent, 1992). The hypothesis according to which the assessment of tied fishermen could be influenced by fishmerchants (who are opposed to the effort regulation schemes) is therefore not borne out by the facts.

\section{Expectations and Actions in a Cartel Game with Heterogeneous Players}

\subsection{Low Enforcement of the Cartel Rules}

So far, we have dealt only with the influence of past, divisive events on expectations regarding present and future collective actions. There remains the task of establishing the link between people's expectations and actions. Unfortunately, data about violations of quotas were not made available to us, either because they did not exist, as contended by local leaders sitting on the executive committees in charge, or because these leaders did not want us to see them. What is striking is the contrast between the optimistic assessments of native leaders on the one hand, and the large incidence of rule breaking as reported in our household survey on the other. As a matter of fact, as many as 38\% of the sample fishermen of Kayar believe that rule violations are frequent. ${ }^{9}$ Yet, leaders belonging to Kayar's elite were at pains to persuade us that there had been only a few cases of clear infringement of the set regulations concerning effort restrictions. That there was no such thing as a diary reporting the known cases of rule violation was therefore not thought to be an important shortcoming.

Severe punishments, they explained to us, had been devised to sanction violations of output-limiting rules. Thus, when a canoe equipped with a purse seine is found exceeding the limit of one fishing trip per day, the rule provides that a fine of 100,000 CFA is imposed on the owner. If he refuses to comply, the canoe and the net are confiscated until he pays the fine, and they can be ultimately sold in case of prolonged default. However, grace delays to pay the fine are extendable to 10-15 days when the rule-breaker is a well-known

\footnotetext{
${ }^{9}$ Note that we have also asked fishermen whether they have themselves violated the rules, yet only 9 out of 127 fishermen in the restricted sample confessed to have done so. For obvious reasons, these answers are unreliable.
} 
fisherman with solvency problems. The same system applies to canoes equipped with lines: concealment of fish boxes exceeding the allowed quota is punished by a fine amounting to 50,000 CFA.

According to committee members, however, such punishments are rarely meted out because there are few rule breakers: for purse seines, only once had a fisherman been allegedly threatened with confiscation of his equipment and the threat did not have to be executed because the culprit paid the fine on the eve of the announced seizure. An alternative explanation, which is more consistent with the above evidence of frequent rule violations, is that enforcement is low. And low enforcement suggests that effort regulation has not been very effective in the long run, even though we have shown elsewhere that there was a genuine potential for price increases through output limitations in Kayar (see Gaspart and Platteau, 2002, pp. 93-5 and appendix B). ${ }^{10}$

In the following, we intend to propose a simple game-theoretical framework aimed at identifying possible outcomes in a cartel with heterogeneous players. In particular, we look for a plausible scenario leading from pessimistic expectations born of a traumatic experience of inter-community conflict to collective action failure.

\subsection{Models of Effort-limiting Schemes with Heterogeneous Players}

The simple theoretical exercise that follows is aimed at understanding the process of cartel formation. In the absence of common identity feelings, our approach is deliberately focused on the interaction

${ }^{10}$ Due to difficult logistical problems, we could only obtain from the CRODT (Centre de Recherches Océanographique de Dakar-Thiaroye) monthly price and landing data pertaining to the years prior to the operation of the effort-limiting schemes. It was therefore impossible to quantitatively assess the impact of these schemes, that is, to determine whether producer prices actually increased as a result of effort regulation in Kayar as compared to other fishing sites where no regulation occurred. What we could establish, however, is that inverse demand elasticities were significantly different from zero for a number of important fish species prior to the launching of the output-limiting scheme in Kayar. This being said, it is perhaps revealing that, in a follow-up workshop in the course of which results of this study were presented, some fishermen expressed doubts regarding the effectiveness of their output-limiting efforts. It is likely, however, that in the beginning of the post-devaluation period (1994), fishermen, especially those targeting export species, did benefit from their acting together. They did, in fact, bring to the attention of the managers of fish factories in Dakar the perverse effect of the remuneration system which they used to pay commission agents in charge of purchasing the raw fish (see above), and this system was consequently modified. 
between native and migrant fishermen. For that reason, the following models treat the two groups as players and abstract from intra-group considerations. Although the migrant group is smaller than the resident group, it is sufficiently numerous to be an important partner in the cartel formation. If residents disregard it, their market power may fall or even collapse.

\section{Game 1: Unenforced Cartel.}

We assume that fishermen produce a homogenous good and sell their product on a common market with a downward sloping demand curve. The decision variable of the fishermen is the quantity. ${ }^{11}$ In such a setting, if no binding commitment is allowed, the only symmetric Nash equilibrium that exists involves both groups picking Cournot quantities, henceforth referred to as non-cooperative strategies (NC). The payoffs associated with the strategy profile (NC, NC) are $d>0$ for each player. This outcome, however, is Pareto dominated by the collusive one. It is, indeed, profitable for both groups to collude and produce together the monopoly quantity. ${ }^{12}$ Producing this quantity will be identified as the cooperative (C) strategy. If both groups play $C$, then, they earn a payoff of $c>d$ each.

As mentioned above, the strategy profile $(C, C)$ is not a Nash equilibrium and every party has an incentive to deviate from the effort restraining scheme by producing a larger quantity. This quantity is not only larger than the cartel quantity associated with the $C$ strategy, but also larger than the Cournot quantity associated with the NC strategy. Nevertheless, even playing NC is better that playing $C$ in this situation. To keep things simple, we assume that the player who wants to free ride applies the NC strategy if he expects the other player to play C. ${ }^{13}$ This approach will help us avoid considering continuum strategy spaces without losing basic insights into the problem. The strategy profile $(\mathrm{NC}, \mathrm{C})$ yields $v>c$ for the free rider and $s<d$ for the (sucker) cooperating player. Clearly, the cartel game played between

11 The assumption of Bertrand competition leads to qualitatively the same game structure as the one derived from the assumption of Cournot competition.

12 The two groups will divide the monopoly quantity between them in proportion to the respective size of their physical capital.

${ }^{13}$ Allowing players to choose the best response strategy would increase the gain of the free rider by providing him with more incentives to deviate. However, even if only the NC strategy is allowed, it destroys the cooperative outcome by supplying incentives to cheat. 


\begin{tabular}{llll}
\hline & & Migrants & \\
Residents & $\mathrm{C}$ & & \\
\hline & & \\
C & c, c & s, v \\
NC & v, s & d, d \\
\hline
\end{tabular}

residents and migrants has the structure of the Prisoner Dilemma, where $v>c>d>s$, as described in Table 3 .

\section{Game 2: Impartially Enforced Cartel}

In the above situation, where no binding commitment is allowed, each group has an incentive to deviate unilaterally from the scheme. To prevent the cartel from breaking down, the Senegalese fishermen devised an enforcement mechanism in the form of fishermen committees (one for each fishing technique concerned). The role of a committee is to detect and punish unilateral violations of the cartel agreement by imposing fines and, if the fines are not paid, by confiscating fishing equipment until the payment is honoured. Since the members of the committee are fishermen themselves, it is in their interest to maintain the cartel so they are eager to punish the violators. ${ }^{14}$

Such motivation on the part of a committee can be represented by a simple utility function. Committee members derive a positive reward $\alpha$ when they punish a fisherman who has exceeded the quota. This reward represents the material gain that accrues to them when the cartel is enforced in a marginally more effective manner and, possibly, it also includes a psychic benefit arising from fulfilling one's duty as scheme enforcers. The utility of not punishing a violator is normalised to zero. The amount of fine, denoted by $F$, does not enter into the utility function of the committee members because it is not appropriated by them. If $F$ is large enough to deter fishermen from violation $(F>v-c)$,

${ }^{14}$ We abstract here from the issues arising from possible rule violations by members of the committee. Enforcing good behaviour on the part of committee members is supposed to be costless. 


\begin{tabular}{lll}
\hline & & Migrants \\
Residents & C & NC \\
\hline C & c, c & s, v-F \\
NC & v-F, s & d \\
\hline
\end{tabular}

cooperation can be maintained, as is evident from Table $4 .{ }^{15}$ The game has the structure of a coordination game, where there are two Nash equilibria $(\mathrm{C}, \mathrm{C})$ and $(\mathrm{NC}, \mathrm{NC})$, with the former one Pareto-dominating the latter. The Pareto-efficient equilibrium is likely to be chosen if some pre-play communication is allowed.

\section{Game 3: Asymmetrically Enforced Cartel}

The crucial assumption allowing for the optimistic result obtained in game 2 is the existence of an impartial third party enforcement mechanism. Yet, this assumption is not satisfied in the peculiar case of Kayar since the two committees in charge of enforcing the effort-regulating schemes are dominated by fishermen native of Kayar. They are therefore susceptible to external pressure on the part of resident fishermen. More precisely, a resident caught violating the rule can more easily persuade the committee to condone his failing than a migrant fisherman could. This is because of the feeling of group identity that binds local residents. Indeed, if those who dominate the committee have strong identity affiliations, they will incur a psychic cost when punishing a fellow fisherman native of Kayar. If this cost, henceforth called identity cost, is large enough, the committee becomes biased and stops penalising the residents, punishing only the migrants. Migrant fishermen cannot influence the committee and are always punished, regardless of the strength of the identity feelings among the residents.

15 The committee punishes every violating fisherman, but only as long as the cartel operates. The committee does not operate if both sides fail to cooperate and the cartel dissolves (i.e., every fisherman is cheating). Because (NC, NC) triggers the dissolution of the cartel, the committee ceases to operate. 
This behaviour of committee members is justified by the following modification of their utility function (for an introduction to economic modeling of group identity, see Akerlof and Kranton, 2000). Like before, committee members derive a positive reward $\alpha$ when they punish a fisherman who has exceeded the quota. In addition, they now incur a psychic identity cost, $I_{\mathrm{c}}$ (with $I_{\mathrm{c}}>0$ ), when punishing a permanent resident and no such cost when sanctioning a migrant. Therefore, committee members will always punish migrants (since $\alpha>0$ ), yet will sanction residents only if $I_{\mathrm{c}}<\alpha$, that is, only if their sense of duty dominates their feelings of group identity. If that is the case, the payoff matrix is the same as that depicted in game 2 (see Table 4 ). When, however, the identity cost is so large as to exceed the gain $\alpha$, the committee is biased in the sense that it shows leniency towards native fishermen. Discrimination against migrant fishermen in the meting out of punishments is reflected in the payoff matrix presented in Table 5. The corresponding game has the structure of a one-sided Prisoner Dilemma in which the non-cooperative outcome is the only Nash equilibrium. ${ }^{16}$

Table 5: Payoff Matrix of an Asymmetrically Enforced Cartel

$\begin{array}{lll}\text { Residents } & \text { C } & \text { Migrants } \\ & & \text { NC } \\ \text { C } & \text { c, c } & \text { s, v-F } \\ \text { NC } & \text { v, s } & \text { d, d }\end{array}$

\footnotetext{
${ }^{16}$ We have assumed that $\alpha$ is constant. More realistically, we could make it depend on the number of actual violators, in which case this parameter becomes endogenous. The exact shape of the relationship between $\alpha$ and the number of violators cannot be determined as long as we do not have information about the nature of the demand curve and strategic reactions of other players. Whatever it is, the effect of endogenising the number of violators is that there will be a positive number of them even at the cooperative equilibrium. Since this is the only additional insight that we could gain from modifying the assumption of constant $\alpha$, and since such modification would compel us to write a more complex $n$-person game, we do not depart from the initial framework.
} 


\section{Game 4: Incomplete Information and Cartel Enforcement}

The next game makes somewhat more realistic assumptions about the informational structure of the model. The crucial hypothesis here is that residents know the magnitude of the identity cost incurred by committee members, but migrants are uninformed about it. This hypothesis is justified by the fact that resident fishermen and committee members belong to the same social group with the consequence that they are aware of the strength of their mutual identity feelings. More precisely, fishermen native of Kayar have better knowledge than migrant fishermen regarding the extent to which committee members are susceptible to identity costs and the extent to which they are themselves ready to exercise pressure on them. On the contrary, being members of a distinct social group, migrants have only an imperfect idea of the emotions and feelings which drive the resident population. As a result, they only have a subjective assessment of the cost for a committee member to sanction a fellow fisherman from Kayar.

In fact, knowledge about the level of identity cost within the committee is equivalent to knowledge as to whether the game that is played is game 2 or game 3. To capture this idea formally, let $\{\mathrm{Hi}, \mathrm{Lo}\}$ be the residents' type space, where Hi corresponds to the case of a high identity cost when $I_{c}>\alpha$ (game 3), and Lo corresponds to the case of a low identity cost when $I_{c}<\alpha$ (game 2). Our hypothesis states that residents know their type with certainty, but migrants attach probability $\Pi$ to $L o$ and $1-\Pi$ to $H i$.

We will show that there are two possible Bayesian Nash equilibria of this game. First, if the migrants' strategy is NC, then the best response of the residents is also to play $\mathrm{NC}$, regardless of their type. For the migrants to play $\mathrm{NC}$ is a best response to this (pooling) strategy of residents, so that the two strategies constitute a Bayesian Nash equilibrium, which will be subsequently referred to as the non-cooperative equilibrium. Second, if migrants' strategy is $C$, the best response of the residents is to play $\mathrm{C}$ if they are Lo and to play NC if they are $\mathrm{Hi}$. Playing $\mathrm{C}$ is the best response of migrants to this (separating) strategy if and only if it yields a higher expected payoff than playing NC, that is, when

$$
\pi>\pi^{*}=(d-s) /[d-s+c-(v-F)] .
$$

Hence these two strategies form a Bayesian Nash equilibrium only if 
migrants are optimistic enough to believe that the committee will be not biased $\left(\pi>\pi^{*}\right)$. This equilibrium will be henceforth referred to as the cooperative equilibrium.

The equilibrium analysis of the model provides an important insight into the situation of fishermen in Kayar. The cooperative outcome is possible only if the migrants are optimistic enough $\left(\pi>\pi^{*}\right)$ to believe in that the committee is impartial. If migrants are pessimistic $\left(\pi<\pi^{*}\right)$, the only possible outcome is the non-cooperative one. Therefore, the behaviour of migrant fishermen depends crucially on their subjective assessment of impartiality of the committee.

The failure of collective effort regulation in Kayar can be interpreted as the outcome of the non-cooperative equilibrium of game 4. As Section 3 shows, migrant fishermen were more pessimistic about the economic effect of effort regulation than the fishermen native of Kayar. Moreover, the pessimism of migrant fishermen was caused neither by their different understanding of the mechanism of effort regulation, nor by their different economic situation. After controlling for those (and other) effects, the econometric analysis exhibits ethnic identity as a significant variable.

Such a conclusion seems to suggest that the asymmetry of beliefs between migrants and residents was caused by an asymmetry of information about the impartiality of the committee. More specifically, because of historically motivated distrust towards the native fishermen, the migrants believed that the committee was impartial only with very low probability. This, as our analysis shows, allows only for the non-cooperative equilibrium to occur. What deserves to be emphasised is that in the non-cooperative equilibrium the effort limiting scheme fails even if the committee is not biased and the objective conditions for cooperation exist. This is what in fact happened in Kayar. It is the migrants' fear of being cheated that ruined the possibility of cooperation. Because they feared non cooperative behaviour on the part of resident fishermen, migrants themselves played non cooperatively to pre-empt the expected behaviour of the former. Even though the objective conditions for increasing prices existed, the pessimism of the migrants did not allow for cooperation and the effort regulation scheme failed. In their voluntarist attitude towards inter-community cooperation, local leaders have underestimated the lingering effects of the past ethnic conflict. 


\subsection{Inferring Initial Beliefs from Reported Opinions}

Having this game-theoretic framework in mind, we can now return to the discussion of Section 3.2 and provide one more argument for ex ante pessimism of migrants. The inference of ex ante fishermen's beliefs (beliefs held prior to the play of the game) from ex post beliefs such as they have been reported during the household survey can be made systematic thanks to the fact that we are able to compare reported beliefs for two groups of fishermen. Let $M$ denote migrants, and $N$ native fishermen. There also are two possible beliefs: $P$, for pessimistic, and $O$, for optimistic. Hence we have four possible combinations of beliefs of the two groups prior to the play of the game:

- Case 1: $M-O, N-O$

- Case 2: $M-P, N-P$

- Case 3: $M-O, N-P$

- Case 4: $M-P, N-O$

We did not observe which case happened ex ante but we know that reported ex post attitudes were $M-P, N-O$. We also know that rule violations are frequent. The exercise is to infer the ex ante beliefs from these two pieces of information, using the framework of game 4 . Note that, although we are trying to inspect beliefs of both groups of fishermen, only migrants' beliefs are explicit in the framework of the game. Nonetheless, we can successfully rule out some cases by applying this logic.

First, we can rule out case 1 because the beliefs assumed under this scenario should have resulted in a favourable outcome of the game (few rule violations). Moreover, as explained in Section 3.2, if both migrants and native fishermen had the same beliefs prior to the game, both would change them as a result of ex post rationalisation or updating.

Case 2 is also unlikely. Although it results in the outcome of the game that was actually observed (ineffective operation due to low enforcement), it is difficult to imagine that permanent residents changed their beliefs from pessimistic to optimistic while observing frequent rule violations. The above argument of asymmetry of rationalisation also applies here.

Case 3 is equally dubious, for the same reason that case 2 is. It is not plausible that, while observing a lot of rule breaking, permanent 
residents would have shifted from a pessimistic to an optimistic attitude.

Having ruled out all the alternative hypotheses, we are left with case 4 as the only plausible scenario. In other words, observed ex post beliefs of the two categories of fishermen correctly reflect their beliefs held before the effort-limiting scheme was launched. Therefore, our interpretation of the results presented in Table 1 (see Section 3) is confirmed: from the very beginning, migrant fishermen were suspicious about the effort-limiting schemes, an attitude influenced by the memory of painful inter-community tensions of which they felt to be the victims. The pessimism on the part of the migrants is reflected in their low expectations about impartiality of the committee: $\Pi$ is small, so it deters migrants from cooperation. This drives native fishermen to also violate the prevailing rules, resulting in a low general rate of compliance that undermines the effectiveness of effort restriction measures.

There remains the puzzling question as to why native fishermen of Kayar continue to hold positive expectations in spite of the high incidence of rule violations of which they are aware. Our hypothesis here is that the positive judgement of native fishermen has been made in the light of the immediate beneficial effect of collective organisation, namely the ending of the most glaring collusive practices of the fishmerchants acting as agents on behalf of export companies (see above, and Section 2.2). Yet, it bears emphasis that, if this is the correct interpretation, it is not effort regulation per se that produced benefits for the fishermen, but a collective struggle aimed at compelling fishmerchants to abandon their most blatant trade malpractices under the pressure of a showdown. Consequently, awareness of the low enforcement performances of the output-limiting schemes did not really affect the assessment of the whole collective endeavour by native fishermen.

Interestingly, the optimistic beliefs of the fishermen in Soumbedioune turn out to be also based on positive impressions generated by an apparently successful collective struggle of fishermen against fishmerchants in Kayar. The very fact that fishermen could resist and confront the power of the fishmerchants thanks to their effort to set up an appropriate collective organisation seems to constitute sufficient evidence to the effect that fishermen's efforts are effective. As for migrant fishermen in Kayar, the tendency is to deny the positive effect 
of the collective struggle while giving more weight to the failure of effort regulation proper.

\section{Conclusion}

Circumstances specific to a peculiar location can significantly influence the prospects of collective action through the shaping of expectations of key actors. In particular, it may be difficult for members of different social groups to cooperate if they were opposed on the occasion of a major conflict in the past. This is exactly what happened in the village of Kayar, where a fraction of migrant fishermen using passive gears antagonised native fishermen operating in the inshore waters. Out of loyalty feelings, other migrant operators strongly identified with their brethren from Saint-Louis. This traumatic experience as it was felt by the migrants (the conflict resulted in death casualties) became reflected in pessimistic expectations regarding the prospects of collective actions undertaken jointly with permanent residents of Kayar.

Local leaders were still persuaded that acting cooperatively in a voluntaristic manner would erase the bad memories of people harbouring dissenting views. A collective struggle against fish merchants provided an unexpected opportunity to overcome past tensions. It, indeed, led to the launching of effort regulation schemes to be enforced by fishermen's committees. It is nevertheless apparent that many migrant fishermen did not trust the committees, which they believed did not represent them properly. A plausible scenario is that, suspicious of being discriminated, they tended to violate the set rules and, being aware of such a lack of trust among migrant fishermen, permanent residents adopted the same attitude. In fact, this is exactly the prediction that can be drawn from an appropriately specified coordination game in which there is private information about the impartiality of enforcement.

The story told in this paper provides a vivid illustration of the legacy of past antagonisms. A nasty precedent was created that undermined cooperation in subsequent games due to the formation of pessimistic expectations. The other central lesson to draw from it is that skill or technical heterogeneity lies at the root of present-day inter-community tensions among fishermen operating from Kayar. Combined with the conflictual nature of fishing operations involving the use of different techniques in the inshore waters, the complete absence of native 
fishermen in the group of bottom-set net operators, as well as the entire dependence of a fraction of migrant fishermen on this technique, have produced a polarised opposition between clearly demarcated groups. Such a situation is particularly explosive because use of a particular technique or possession of a particular skill is associated with community identity, which tends to add a symbolic and emotional dimension to what could have remained a pure conflict of interests.

To sum up, at the rock-bottom of the conflict lies an economic contest around scarce resources. This contest got amplified because of a technological divide that unhappily coincided with a community divide. In the absence of the former, the latter would not have mattered. In such a context, proper constitutional mechanisms must be devised and enforced so as to allay the fears of contending social groups and thereby surmount inter-community tensions, as emphasised by Horowitz (1985). This is precisely the condition that was not fulfilled in the case of Kayar, in spite of the apparently good intentions of the native fishermen and the local elite. By overestimating the merits of a voluntaristic approach, the local elite underplayed the negative effect of past trauma and the consequent need for institutional arrangements providing enough reassurances to the victimised group. Suppressing expressions of lingering frustrations and ill-feelings, especially if it is done in a rather brutal manner, is probably not a good tactic: it may actually contribute to the persisting influence, instead of the eradication, of painful memories and obstructive misgivings.

\section{References}

Akerlof, G.A. and R.E. Kranton (2000) 'Economics and Identity', Quarterly Journal of Economics, CXV: 715-53.

Basu, K., E. Jones and E. Schlicht (1987) 'The Growth and Decay of Custom: The Role of the New Institutional Economics in Economic History', Explorations in Economic History, 24 (1): 1-21.

Bates R., R. de Figueiredo and B. Weingast (1998) 'The Politics of Interpretation: Rationality, Culture and Transition', Politics $\mathcal{E}$ Society, 26: 604-642.

Gaspart, F. and J.P. Platteau (2002) 'Collective Action for Local-level Effort Regulation: An Assessment of Recent Experiences in Senegalese Small-scale Fisheries', in J. Heyer, F. Stewart and R. Thorp (eds), 
Group Behaviour and Development - Is the Market Destroying Cooperation? Oxford: Oxford University Press, pp. 75-103.

- (2004) 'Heterogeneity and Collective Action for Effort Regulation: Lessons from the Senegalese Small-scale Fisheries', forthcoming in J.M. Baland, P. Bardhan, and S. Bowles (eds), Inequality, Cooperation and Environmental Sustainability, Cambridge MA: MIT Press.

Horowitz, D.L. (1985) Ethnic Groups in Conflict, London: University of California Press.

Platteau, J.P. and A. Abraham (1987) 'An Inquiry into Quasi-credit Contracts: The Role of Reciprocal Credit and Interlinked Deals in Small-scale Fishermen Communities', Journal of Development Studies, 23 (4): 461-90.

Platteau, J.P. and J. Nugent (1992) 'Share Contracts and Their Rationale: Lessons from Marine Fishing', Journal of Development Studies, 28 (3): 386-422.

Weingast, B.R. (1998) 'Constructing Trust: The Politics and Economics of Ethnic and Regional Conflict', in V. Haufler, K. Soltan, and E. Uslaner (eds), Where is the New Institutionalism Now? Ann Arbor MI: University of Michigan Press. 